\title{
Bipolar Polyethylene Radial Head Artroplasty in Posttraumatic Unstable Elbows \\ Prosthetic design and clinical results
}

\begin{abstract}
PAUL DAN SIRBU ${ }^{1}$, RAZVAN TUDOR ${ }^{2 *}$, GRIGORE BEREA ${ }^{3}$, ANDREI SCRIPCARU ${ }^{1}$, BOGDAN CIUBARA ${ }^{4 *}, 0$ ONA VIOLA BADULESCU 5
${ }^{1}$ Grigore T. Popa University of Medicine and Pharmacy, lasi, Romania, Faculty of Medicine, Department of Orthopedics and Traumatology, Surgical Sciences (II), 16 Universitatii Str., 700115, Galati, Romania

${ }^{2}$ Vaslui County Hospital, Department of Orthopedics and Traumatology, 233 Stefan cel Mare Str. 730006, Vaslui, Romania

${ }^{3}$ Emergency County Hospital Piatra Neamt, Department of Orthopedics and Traumatology, 1 Traian Blvd., 611003, Piatra Neamt, Romania

${ }^{4}$ Dunarea de Jos University, Faculty of Medicine and Pharmacy, Departament of Morphological and Functional Sciences, 35 Al. I. Cuza Str., 800010, Galati, Romania

${ }^{5}$ Grigore T. Popa University of Medicine and Pharmacy, Iasi, Romania, Faculty of Medicine, Department of Pathophysiology, Morfo Functional Sciences (II), 16 Universitatii Str., 700115, Galati, Romania
\end{abstract}

\begin{abstract}
The purpose of this experimental studyis to present the design and biomechanical characteristics of bipolar polyethylene radial head prostheses type KPS (CHM ${ }^{\circledR}$ Poland), as well as to evaluate their use in comminuted fractures type Mason III associated with ligament injuries. We retrospectively evaluated 7 patients with 7 complex radial head fractures with an average age of 38.5 years. The prostheses were implanted through a lateral Kocher approach and patients immediately began the rehabilitation of the elbow. The functional results according to the MEPS score (Mayo Elbow Performance Score) were excellent in 3 cases and good in 4 cases, without stem loosening or residual instability of the elbow. Due to the overwhelming advantages of this bipolar prosthesis (better joint tracking and easier implantation technique) and its very good functional results, the authors recommend this type of arthroplasty in posttraumatic elbow instability.
\end{abstract}

Keywords: bipolar radial head prosthesis, ligament injuries, elbow instability, polyethylene

Radial head fractures are among the most common fractures of the elbow, with an incidence of $1.7 \%-5.4 \%$ of adults' fractures[1]. If in fractures without displacement (type Mason I), short-term immobilization with a splint is followed by success, and in fractures type Mason II, open reduction and internal fixation (ORIF) is the recommended treatment, in the case of fractures type Mason III (comminuted and irreparable fractures), the surgical decision consists in radial head excision, with or without its prosthetic replacement [2-4]. The association of complex fractures of the radial head to lesions of the medial collateral ligament, lateral collateral ligament or interosseous membrane and fractures of the coronoid apophysis type II (according to Regan) contraindicates the radial head excision alone. In case that the radial head fracture is associated with a dislocation of the elbow, the simple excision is also contraindicated, because it is generally associated with damages to the collateral ligaments. The explanation lies in the role that the radial head plays in axial stabilization, as well as in the stabilization of the varus and valgus of the elbow [5], given that it is considered as a II degree stabilizer (after the medial collateral ligament-1st degree stabilizer) and remains the primary stabilizer in case of deficiency or injury of the medial collateral ligament. Thus, arthroplasty ensures better results than simple resection in complex radial head fractures associated with ligament injuries [6].

Numerous types of prosthetic materials have been conceived since 1941 (Speed's vitallium prosthesis) [7] in an attempt to achieve an ideal model to restore the normal kinematics of the elbow [6].

The disadvantages of Swanson silicone prostheses [7], but also of monoblock metal prostheses [8], have prompted the use of bipolar prostheses (that improve joint tracking) [9] or modular prostheses (which act as spacers, restoring the functional anatomy of the elbow) [10].

The purpose of this experimental study is to present the design and biomechanical characteristics of bipolar radial head prostheses type KPS (CHM ${ }^{\circledR}$ Poland), as well as to analyze the results of the treatment of 7 complex radial head fractures by using this innovative prosthesis.

\section{Experimental part}

The experimental part of the study was performed on a serie of 7 patients that have benefited from a radial head arthroplasty with bipolar prostheses type KPS $\left(\mathrm{CHM}^{\circledR}\right.$ Poland) at the Department of Orthopaedics and Traumatology of the Emergency Clinical Hospital Sf. Spiridon lasi and the Emergency County Hospital Piatra Neamt, during 2011-2015.

\section{Prosthetic Design}

Bipolar radial head prostheses type KPS (CHM $\$ \$$ Poland) consist of 2 components, a radial stem made from Cobalt alloy (in accordance with ISO 5832) and a radial head made from high density polyethylene (UHMWPE in accordance with ISO 5832) and Peek Optima $\$ \$$ Wear Performance (in accordance with ISO 10993-1) [11]. The prosthetic stem has a collar, which is supported by the radial neck sectioned during surgery.

The bipolar mechanism of the prosthesis (fig. 1) is achieved through two distinct movements: a. The polyethylene head is connected to the radial stem as a socketjoint, which allows the head to rotate and angulate at $15^{\circ}$ towards the axis of the stem in both directions (the total amplitude of angulation is $30^{\circ}$ ). At the same time, the

\footnotetext{
* email: rc tudor@yahoo.com; abciubara@yahoo.com
} 
prosthetic head has an outer barrel-shaped convex surface that adapts to the concave surface of the radial notch of the ulna.

b. The upper concave surface of the radial prosthetic head is in contact with the cartilaginous surface of the humeral capitellum.

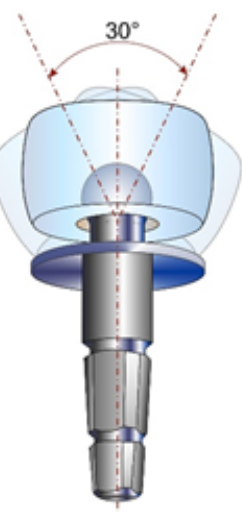

Fig. 1. Design and kinematics of the bipolar radial head prosthesis type KPS $\left(\mathrm{CHM}^{\circledR}\right.$ Poland) Adapted image from [11]

We retrospectively researched 7 patients with 7 radial head fractures type Mason III with an average age of 38.5 years (range 22-64). All the patients had elbow dislocations as well, while 2 of them had associated fractures of the coronoid apophyses (type II according to Regan)

\section{Surgical technique}

Patients were placed in supine position and the radial head arthroplasty (fig. 2) was carried out with plexal subclavian anesthesia (5 cases) or general anesthesia (2 cases), with a tourniquet applied to the root of the operated upper limb. In all cases, we used a Kocher lateral approach $-1 \mathrm{~cm}$ above the lateral epicondyle and $2 \mathrm{~cm}$ distally from the radial head over a length of $6-8 \mathrm{~cm}$ (fig. 2A). Then we dissected the fascia between the anconeus and the extensor carpi ulnaris. The approach to the joint allowed the extraction of all the radial head fragments and its restoration on the operation table, as well as the choice of a prosthetic implant suitable to its dimensions. (fig. 2B). With the help of an oscillating saw there was carried out a corrective osteotomy at radial neck level (fig. 2C, D), followed by the preparation of the medullary canal with successive rasps (fig. 2E). After this stage there were chosen a trial radial stem and a trial radial head, which were used to verify the stability of the elbow in flexion, extension and rotation. (fig $2 F, G$ ). Based on the results obtained with the trial implants, the definitive radial stem

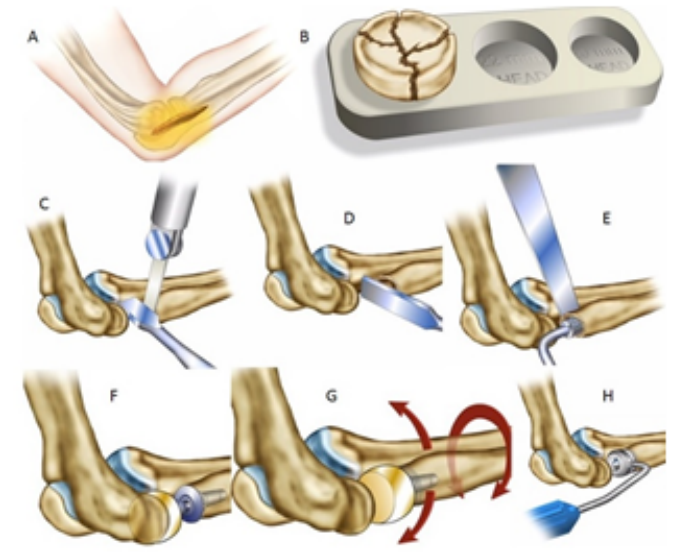

Fig. 2 (A-H) - Surgical technique of radial head artrhoplasty with a bipolar prosthesis type KPS $\left(\mathrm{CHM}{ }^{\circledR}\right.$ Poland); Adapted images from [11] was fixed into the radial canal (with cementation) and the definitive radial polyethylene head was chosen and applied to the stem. (fig. 2 H, fig. 3A, B, fig. 4 A-G)

The last stage of the intervention was restoring the lateral ligamentary complex, based on which the subsequent rehabilitation program was established.

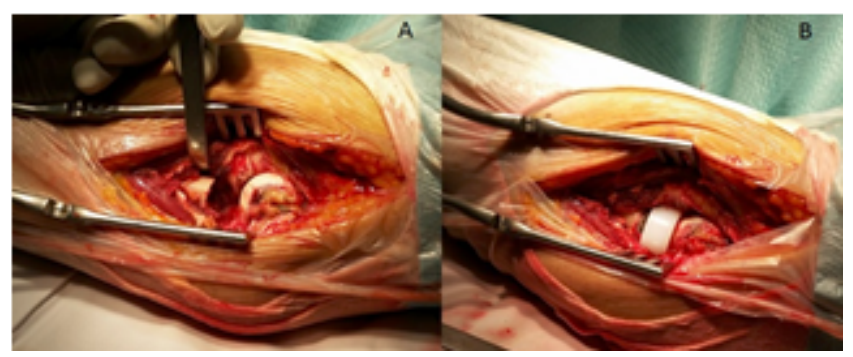

Fig. 3A, B, Arthroplasty of the radial head - intraoperative appearance: A - radial neck osteotomy; B - implantation of the definitive polyethylene prosthesis

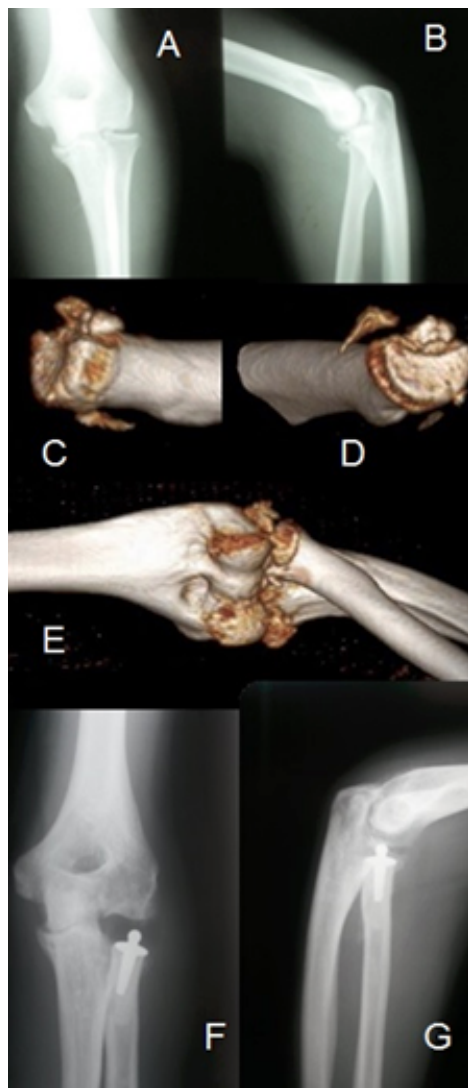

Fig. 4 A-G - Arthroplasty of the radial head with $a$ bipolar prosthesis; A-B preoperative X-rays; C-E - CT Images with $3 \mathrm{D}$ reconstruction documenting a Mason III fracture with coronoid apophysis fracture Regan II; F-G - postoperative images (polyethylene head invisible to $x$-rays)

After surgery, patients were immobilized with a long arm splint at $90^{\circ}$ for 5-7 days. Functional rehabilitation started after this period, with an elbow mobile orthosis which allowed safe active flexion and extension exercises for 3-4 weeks. After this period forearm pronation and supination exercises were performed; active and passive stretching and strengthening exercises were started at 6 weeks postoperatively.

All patients were clinically and radiographically followed up for an average period of 24 months (range, 18-36 months). Control x-rays (anterior-posterior and lateral views) were evaluated postoperatively, at 1 month, 6 months and 1 year later. The radiological images was reviewed for any eventual aseptic loosening of the cemented radial stem, heterotopic ossification, and joint incongruity. Clinical evaluation was carried out by using the MEPS score (Mayo Elbow Performance Score) which includes pain, elbow mobility and stability, as well as the functional level [12]. 


\begin{tabular}{|l|l|l|l|l|l|}
\hline $\mathrm{N}^{\circ}$ & Pain & $\begin{array}{l}\text { Range of } \\
\text { motion } \\
\text { (ROM) }\end{array}$ & Stability & Function & MEPS \\
\hline 1 & 45 & 20 & 10 & 25 & 100 \\
\hline 2 & 45 & 15 & 10 & 25 & 95 \\
\hline 3 & 30 & 15 & 10 & 25 & 80 \\
\hline 4 & 30 & 20 & 10 & 25 & 85 \\
\hline 5 & 30 & 15 & 10 & 20 & 75 \\
\hline 6 & 30 & 15 & 10 & 25 & 80 \\
\hline 7 & 45 & 15 & 10 & 20 & 90 \\
\hline
\end{tabular}

Table 1

MEPS SCORE FOR 7 PATIENTS WITH RADIAL HEAD FRACTURES MASON III(EXCELENT>90, GOOD, 75-89, FAIR 60-74, POOR<60)

\section{Results and discussions}

Based on the MEPS score, 3 patients had excellent results, while the other 4 patients had good results (table 1).

Clinical evaluation showed that all the patients could perform their daily activities without any discomfort, with a functional flexion-extension angle of the elbow of at least $100^{\circ}$ and a rotation angle of the forearm of at least $100^{\circ}$ (pronation $50^{\circ}$ and supination $50^{\circ}$ ). In no case it was necessary to carry out the removal of the prosthesis due to loosening or infection. There were no patients with elbow instability or neurovascular injuries after arthroplasty with bipolar prosthesis.

The treatment of radial head fractures type Mason III associated with ligament injuries is still controversial. The surgical alternatives for these difficult lesions are ORIF, resection of the radial head and arthroplasty [4].

Although simple resection is easy and fast from a technical standpoint, it has proven to generate early and late complications over time, especially if the fracture is combined with other injuries. The studies of Kennedy [13] and Hotchkiss [14] support these observations, by confirming early and late instability of the elbow, especially after the resection for fractures associated with dislocation. According to Birkbeck [15], the resection of the radial head would lead to increased tension in the oblique fibers of the interosseous membrane and in the distal radioulnar joint, being associated with radius ascensioning, according to Rabinowitz [16]. The increase in elbow valgus deviation at 10 years after head resection [17] is associated with an arthritic degeneration at the level of the ulnohumeral joint [18] with chronic pain in elbow and wrist, especially in fracture-dislocations [19].

It was experimentally proved that, in the case of comminuted factures with ligament injuries, replacing the radial head with a prosthesis can restore the stability of the elbow at a level similar to the one ensured by the patient's native radial head [20].

Arthroplasty of the radial head debuted in 1941 when Speed [7] used a vitallium implant in a series of three patients. Although Cherry [7] discussed the use of an acrylic implant about 10 years later, the most popular prosthesis was Swanson's silicon prosthesis. In addition to restoring a function inasmuch as possible, the purpose of these implants was to ensure mechanical characteristics similar to those of the bone (similar coefficient of elasticity). The ideal radial head prosthesis should have the same anatomical shape and the same dimensions as patient's native radial head. It should be made of a material with an elasticity coefficient similar to the one of the bone and it should ensure stability, without damaging the cartilage of the humeral joint. The stem of this prosthesis in the medullary canal should resist repeated microtraumas and, last but not least, the prosthesis should be easily implanted.

The positive results obtained by Swanson [7] with silicone prostheses since 1968 were increasingly contested after the 80', because of clinical observations related to the poor axial and valgus stability ensured by this type of prosthesis, as well as to the high incidence of detritus and fragmentation over time and, last but not least, to the synovitis caused by the silicon, which led to degradation of the joint. All these results have prompted a return to more rigid implants, such as those made of cobalt-chromium alloys, titanium, ceramics and pyrocarbon. Nowadays, it is possible to find on the market monoblock prostheses (KNITS, SOLAR, ASCENSION), bipolar prostheses (BIPOLAR, GUEPAR, KPS) and modular prostheses (AVANTA, EVOLVE, MOPYC), which are applied with or without cementing, according to the manufacturer's specifications.

The disadvantages of monoblock metal prostheses are recognized in specialized literature: they are difficult to implant, because they require elbow subluxation [8]; the number of sizes is rather limited and pressure is exerted on the articular cartilage due to malposition and cementation of the stem[21]. All these problems have led to the development of bipolar prostheses, which improve joint tracking and are easily implanted, allowing small positioning vices. However, the issue of polyethylene wear remains a controversial subject[21]. At the same time, bipolar prosthesis tend to angulate under burden, which leads to a decrease in the stabilizing effect in ligament and elbow injuries [9].

Metal modular prostheses developed in recent years represent an interesting alternative to the bipolar prosthesis with polyethylene head. The Evolve prosthesis of Wright Medical Technology has been widely studied in specialized literature [10] and ithas undeniable advantages: itensures maximum biocompatibility and has ideal modularity (head with 5 diameters and 3 different thicknesses, stem with 3 diameters and 2 heights - 150 possible combinations); the two components of the prosthesis are successively introduced with limitation of the surgical approach (as in the case of the bipolar prosthesis); it is not cemented (it is an intra-articular spacer, which ensures a degree of rotational and axial mobility in the medullary canal with good adaptation to the joint surface of the capitellum, causing a smaller wear over time).

\section{Conclusions}

The bipolar polyethylene prosthesis of the radial head is an innovative implant, due to its indisputable advantages: better joint tracking by multiple movements and angulation as well as easier implantation.

The rapid mobilization of the elbow has led to verygood functional results, which convinced the authors to 
recommend this solution for radial head fractures type Mason III associated with ligament injuries.

\section{References}

1.TAYLOR TKF, O'Conner The effect upon the inferior radio-ulnar joint of excision of the head of the radius in adults , JBJS Br 1964; 46:83-8;

2. MASON ML, Some observations on fractures 0 the head of the radius with a review of one hundred cases, Br J Surg. 1954 Sep;42(172):123-32.

3. Shore, Benjamin J. MD; Mozzon, J eremy B. BSc; MacDermid, J oy C. BSCPT, MSc, PhD; FABER, KENNETH J. MD, MHPE, FRCSC; KING, GRAHAM J.W. MD, MSC, FRCSC J ournal of Bone \& J oint Surgery American Volume: 01 February 2008 - Volume 90 - Issue 2 - p 271-280 4. BEINGESSNER DM, DUNNING CE, GORDON KD, JOHNSON J A, KING $G$ ). The effect of radial head excision and arthroplasty on elbow kinematics and stability. J Bone J oint Surg Am. 2004 Aug;86-A(8):17309.

5. MORREY BF, TANAKA S, AN KN. Valgus stability of the elbow. A definition of primary and secondary constraints. Clin Orthop 1991; 265: 187-195

6. KING GJ, ZARZOUR ZD, RATH DA, DUNNING CE, PATTERSON SD, JOHNSON JA. Metallic radial head arthroplasty improves valgus stability of the elbow. Clin Orthop Relat Res. 1999 Nov; (368):114-25.

7. CELLI A, CELLI L, MORREY BF. Treatement of elbow lesions. Italia Springer-Verlag, 2008

8. GUPTA GG, LUCAS G, HAHN DL, Biomechanical and computer analysis of radial head prostheses J Shoulder Elbow Surg. 1997 JanFeb;6(1):37-48.

9. SCHNEEBERGER AG, SADOW SKI MM, J ACOB HA. Coronoid process and radial head as posterolateral rotatory stabilizers of the elbow. J Bone J oint Surg Am. 2004 May;86-A(5):975-82.

10. KING GJ. Management of comminuted radial head fractures with replacement arthroplasty. Hand Clin. 2004 Nov;20(4):429-41, vi. 11.***http://en.chm.eu/products/endoprosthesis/radial-headprosthesis/radial-head-prosthesis-gkp

12. MORREY BF, AN KN, CHAO EYS (1993) Functional evaluation of the elbow. In Morrey BF (ed.) The Elbow and Its Disorders, 2nd ed. Philadelphia: WB Saunders, 86-89.

13. JOSEFSSON PO, GENTZ CF, JOHNELL O, WENDEBERG B. Dislocations of the elbow and intraarticular fractures. Clin Orthop 1989; 246:126-130

14. HOTCHKISS RN. Dislocations of the elbow and intraarticular fractures. In: Rockwood CA, Green DP, Bucholz RW, Heckman JD. Rockwood and Green's fractures in adults. 4 edn. Lippincott -Raven Philadelphia, 1996, 929-1024

15.BIRKBECK DP, FAILLA J M, HOSHAW SJ et al. The interosseous membrane affects load distribution in the forearm. J Hand Surg Am 1997; 22: 975-980

16. RABINOWITZ RS, LIGHT TR, HAVEY RM et al. The role of interosseous membrane and triangular fibrocartilage complex in forearm stability. J Hand Surg Am 1994; 19: 385-393.

17. IKEDA M, OKA Y. Function after early radial head resection for fracture: a retrospective evaluation of 15 patients followed for 3-18 years. Acta Orthop Scand 2000; 71: 191-194

18. JANSSEN RP, VEGTER J. Resection of the radial head after Mason type III fractures of the elbow follow -up at 16 to 30 years. J Bone J oint Surg Br 1998; 80: 231-233

19. HERBERTSSON P, J OSEFSSON PO, HASSERIUS R et al. Fractures of the radial head and neck treated with radial head excision. J Bone Joint Surg Am 2004; 86: 1925-1930

20. HARRINGTON II 1, SEKYI-OTU A, BARRINGTON TW, EVANS DC, TULI V. The functional outcome with metallic radial head implants in the treatment of unstable elbow fractures: a long-term review J Trauma. 2001Jan;50(1):46-52.

21. CHIEN HY1, CHEN AC, HUANG JW, CHENG CY, HSU KY. Short- to medium-term outcomes of radial head replacement arthroplasty in posttraumatic unstable elbows: 20 to 70 months follow-up. Chang Gung Med J . 2010 Nov-Dec;33(6):668-78.

Manuscript received: 13.07 .2016 